\title{
EFECTOS DE LA REFORMA ENERGÉTICA EN EL TERRITORIO Y CONDICIONES socioeconómicas en Papantla, Veracruz, México
}

\author{
EFFeCTS OF THE ENERGy ReFORM IN THE TERRITORY AND SOCIOECONOMIC \\ Conditions of Papantla, Veracruz, Mexico \\ Elvira Nuñez-Terrones* \\ Yolanda Sánchez-Torres** \\ Aníbal Terrones-Cordero***
}

DOI: http://dx.doi.org/10.29043/liminar.vl8il.720

\begin{abstract}
Resumen: En México, la producción de energéticos dio un giro a partir de 2013 con la promulgación de la reforma energética, y posteriormente con la Ley de Hidrocarburos de 2014. La finalidad del presente estudio fue analizar las implicaciones de la reforma energética en las condiciones territoriales, económicas y sociales de El Remolino, municipio de Papantla, Veracruz. Para ello se aplicaron cuestionarios a cuarenta ejidatarios y se realizaron dos entrevistas colectivas durante 2015 y 2016. En El Remolino, la explotación de hidrocarburos no ha generado un cambio significativo positivo para reducir los niveles de pobreza de la población; por el contrario, ha continuado el despojo de tierras ejidales, la contaminación de suelos y aguas, el abandono de la producción agrícola y el descontento social.
\end{abstract}

Palabras clave: reforma energética; explotación de hidrocarburos; despojo de tierras; territorio; ruptura sociocultural.

Abstract: In Mexico, the production of energy changed when the energy sector was reformed in 2013 and a hydrocarbons law was passed in 2014. The purpose of this study is to analyze the implications of the energy reform on territorial, economic, and social conditions in El Remolino, municipality of Papantla, Veracruz. To gather data in this regard, citizens were engaged, questionnaires were answered by 40 ejido residents, and two collective interviews were held during 2015 and 2016. In El Remolino, hydrocarbon extraction has not generated significant change in reducing residents' poverty levels; on the contrary, the dispossession of ejido lands, contamination of soil and water, abandonment of agricultural production, and social discontent continue unabated.

Keywords: energy reform; hydrocarbons exploitation land dispossession; territory; socio-cultural disruption.

\footnotetext{
* Elvira Nuñez Terrones. Maestra en Ciencias en Sociología Rural por la Universidad Autónoma Chapingo, México. Doctorante en Ciencias Agrarias por la Universidad Autónoma Chapingo, México. Temas de especialización: ciencias sociales orientadas al medio rural y territorio. Correo electrónico: elnute.doc.uach@gmail.com. ORCID: http://orcid. org/0000-0001-5802-9322.

** Yolanda Sánchez Torres. Doctora en Ciencias por el Colegio de Posgraduados, México. Profesora-investigadora de tiempo completo del Instituto de Ciencias Económico Administrativas (ICEA) dela Universidad Autónoma del Estado de Hidalgo, México. Temas de especialización: desarrollo regional y políticas públicas. Correo electrónico: yolasato08@ hotmail.com ORCID: http://orcid.org/0000-0002-7372-6123.
}

\begin{abstract}
*** Aníbal Terrones Cordero. Doctor en Ciencias por el Colegio de Posgraduados. Coordinador de la Maestría en Estudios Económicos y profesor de tiempo completo en el Instituto de Ciencias Económico Administrativas (ICEA) dela Universidad Autónoma del Estadode Hidalgo, México. Temas de especialización: políticas públicas y desarrollo regional. Correo electrónico: aterrones68@hotmail.com Autor para correspondencia. ORCID: http://orcid.org/0000-0002-2959-1807 .
\end{abstract}

Enviado a dictamen: 7 de mayo de 2019. Aprobación: 5 de septiembre de 2019 Revisiones: 2. 


\section{Introducción}

$\amalg$ n México la denominada reforma energética, promulgada el 20 de diciembre de 2013, implicó la modificación del artículo 27 constitucional en materia de energía, lo que permitió que particulares, a través de contratos de asignación, puedan participar en todas las actividades propias de la industria eléctrica, del petróleo y demás hidrocarburos (Constitución Política..., 2018:art. 27). Esta reforma incidió de manera negativa en la tenencia de la propiedad agraria y en los derechos colectivos sobre el uso y aprovechamiento de la tierra y de los bienes naturales (Núñez, 2017).

Con las adecuaciones al marco jurídico nacional se creó la servidumbre legal de hidrocarburos u ocupación temporal del suelo como dispositivo jurídico regulado en la Ley de Hidrocarburos promulgada en 2014, cuya última reforma se efectuó en 2016, instrumento legal creado con el fin de allanar el camino a las empresas energéticas para abaratar sus costos y maximizar sus ganancias frente a los requerimientos de los afectados; con la servidumbre se condensó y abrevió el procedimiento administrativo (Constitución Política..., 2018:art. 108), además de que se sustituyó la figura de expropiación tradicionalmente utilizada para los casos de afectación de tierras. Estas modificaciones jurídicas ponen en evidencia la perspectiva materialista de vertiente economicista según la cual el capital y el Estado visualizan el territorio como una simple fuente de recursos, y retrata los procesos mediante los cuales se construyen los mecanismos de dominación territorial y de precarización social (Haesbaert, 2013), ejercidos por las prácticas capitalistas de dominación territorial en una fase de acumulación por desposesión (Harvey, 2005)

Petróleos Mexicanos (PEMEX, 2012) y la Secretaría de Energía (2018a) presentan una imagen clara sobre los territorios que resultan directamente afectados con la ejecución de los megaproyectos amparados en la reforma energética, ya que con la implementación de la legislación en materia de energéticos, y con base en el otorgamiento de asignaciones, áreas, campos y bloques determinados por la Secretaría de Energía, se crearon las denominadas rondas, que son un conjunto de licitaciones en un área determinada para exploración o producción de hidrocarburos. Entre estas zonas destaca el estado de Veracruz debido a la gran cantidad de proyectos previstos en la entidad.

Los trabajos de PEMEX en territorio veracruzano se remontan a los primeros meses de 1938, tras ser decretada la expropiación petrolera por el presidente Lázaro Cárdenas, periodo durante el cual la actividad dejó impactos ambientales y sociales muy graves (Ibarra, 2003); en este sentido, se preveía ya en 2014 que con los megaproyectos de exploración y extracción impulsados con la reforma energética aumentaría considerablemente la actividad de los hidrocarburos en dicha entidad federativa, donde se utilizarían, en gran medida, técnicas invasivas y perjudiciales como la fractura hidráulica o fracking (Cartocrítica, 2014). Sobre la explotación de hidrocarburos mediante fracking en Veracruz, Emilio Rodríguez Almazán, integrante de la Asamblea Veracruzana de Iniciativas y Defensa Ambiente (LAVIDA), manifestó que existe información oficial proveniente del Instituto Federal de Acceso a la Información (IFAI), con número de solicitud 1857500000714, en la cual PEMEX públicamente confirmó que había utilizado la técnica de fracking en aproximadamente 297 pozos en el estado de Veracruz (Rodríguez, 2014).

La presente investigación se ubica en el debate ideológico de la perspectiva materialista o instrumental funcional del capital y el Estado y en la visión comunitaria que los pueblos originarios y campesinos tienen sobre su territorio (Haesbaert, 2013). De acuerdo con la visión materialista de vertiente economicista, se concibe el territorio solamente como un recurso orientado a la reproducción del capital, considerado como recurso natural o como abrigo para los grupos sociales, en tanto que desde la visión idealista se concibe con énfasis en su dimensión simbólica, según la cual el territorio es definido desde el horizonte de la representación de valor simbólico (Haesbaert, 2013); desde esta visión simbólica, el territorio se puede entender como "un espacio culturalmente construido por una sociedad a través del tiempo" (Barabas, 
2010:48). Ambos planteamientos permiten entender la intrínseca relación que existe entre la identidad cultural de las comunidades originarias y campesinas con sus territorios.

El objetivo de este trabajo fue analizar las implicaciones de la reforma energética en las condiciones territoriales, económicas y sociales en el ejido El Remolino, municipio de Papantla, Veracruz, con énfasis en la restructuración social y territorial por la implementación de los megaproyectos exploratorios y extractivos impulsados a partir de la reforma de 2013 al artículo 27 constitucional y de la promulgación de la Ley de Hidrocarburos en 2014. Para ello, se utilizó la observación participante para la identificación de la problemática, se aplicaron cuestionarios a cuarenta ejidatarios y se realizaron dos entrevistas colectivas a catorce y diez personas respectivamente durante 2015 y 2016. La hipótesis de investigación fue que la reforma energética afecta territorios de comunidades, pueblos originarios y campesinos, y provoca una restructuración territorial que puede fomentar la desintegración de su entramado social, sus modos de vida y sus recursos de organización y de convivencia, generando deterioros inmateriales.

\section{Fundamentación teórica}

En el presente trabajo se retoman los planteamientos de Rosa Luxemburgo sobre el proceso de acumulación capitalista en cuanto a que el capitalismo se genera y desarrolla históricamente en un medio social no capitalista. Diferencia tres etapas en este proceso: la lucha del capital contra la economía natural, la lucha contra la economía de mercancías, y la concurrencia del capital en el escenario mundial para conquistar el resto de elementos para la acumulación. Menciona que el capital se enfrenta de manera encarnizada contra la economía natural a fin de aniquilar las formaciones sociales y las económicas independientes de indígenas o campesinos que constituyen el muro más fuerte con que se topa el capital (Luxemburgo, 1967). Los fines económicos del capitalismo en su combate a las sociedades de economía natural son:
[...] apoderarse directamente de fuentes importantes de fuerzas productivas, como la tierra, la caza de las selvas vírgenes, los minerales, las piedras preciosas, los productos de las plantas exóticas como el caucho; liberación de las fuerzas de trabajo que se verán obligados a trabajar para el capital; introducción de la economía de mercancías; y separación de la agricultura del artesano (Luxemburgo, 1967:284).

Planteó que el Estado funge como "facilitador" frente al requerimiento de apropiación territorial del capital, quehacer que efectúa mediante el ajuste de leyes, reglamentos o decretos que permiten trastocar "antiquísimos" derechos comunitarios sobre la tierra de grupos primitivos o campesinos con el objetivo de colocarlos a merced del capital. Este "acomodo" de ordenamientos jurídicos está siempre encaminado al establecimiento de la propiedad privada y a la destrucción de la propiedad común. En ese contexto, se puede hablar de una implementación forzosa de la propiedad privada a fin de liberar las tierras requeridas por el capital, ya sea mediante una institución violenta o mediante mecanismos de persuasión que otorguen a una instancia "voluntaria" el establecimiento de esa propiedad (Luxemburgo, 1976).

Harvey (2005), con una clara influencia de Luxemburgo, aborda la denominada geografía de la acumulación del capital, la producción del espacio y el desarrollo geográfico desigual a partir de una perspectiva marxista. Desde su postura afirma que la visión mercantilista y privatizadora que el sistema capitalista tiene sobre el territorio ha desembocado en estrategias que denomina "acumulación por desposesión"; asimismo, abordó la nueva experiencia del espacio y del tiempo generada por las nuevas formas de acumulación de capital y cómo en este proceso acelerado de expansión geográfica y desplazamiento temporal el capital domina territorios enteros y los modela de acuerdo con sus necesidades temporales. "Entender las reglas de la acumulación del capital nos ayuda a comprender por qué nuestra historia y nuestra geografía adoptan las formas que adoptan" y la manera en que la identidad se construye en función de la 
apreciación espacio-temporal que se tenga de nuestra ubicación física (Harvey, 2007:40, 138).

Entre los nuevos mecanismos de acumulación por desposesión sobresale la acelerada depredación de los bienes ambientales globales (tierra, agua y aire), que transforman completamente el sentido de la naturaleza convirtiéndola en una mera mercancía a la cual se le ha asignado un fluctuante valor de cambio. Es importante subrayar que, con esta mercantilización de los bienes ambientales globales, simultáneamente se comercializan la cultura, la historia, los procesos y relaciones sociales y la sexualidad, incluso la creatividad intelectual; de esta manera, se desdibujan los límites de la frontera comercial en el capitalismo global. Este aumento desmedido de elementos que son considerados mercancía y entregados al mejor postor "supone la total desposesión" (Harvey, 2005:114).

La creación de organizaciones como el Banco Mundial y el Fondo Monetario Internacional tuvo como objetivo la estabilización de las relaciones internacionales bajo el sistema neoliberal, donde la libertad individual, el progreso y el bienestar están relacionados con el libre comercio. En el sistema neoliberal, la acumulación de capital, la propiedad privada y la generación de beneficios conduce a que el régimen de derechos neoliberales deba expandirse geográficamente a nivel global (Giménez, 1999; Harvey, 2007).

A la luz de los anteriores planteamientos se retomó a Haesbaert (2013:13), para quien el concepto de territorio está siempre vinculado a las relaciones de poder y "al control de los procesos sociales mediante el control del espacio"; identificó que en el segundo de los enfoques predominantes, el idealista, se define el territorio enfatizando su dimensión simbólica en el campo de las representaciones sociales. En esta visión comunitaria, los referentes espaciales forman parte de la vida de las poblaciones como elementos indisociables en la creación de símbolos, e incluso pueden ser responsables por la propia definición del grupo como tal (Haesbeart, 2013:26).

Los espacios representacionales "son los espacios fenomenológicos de la vivencia, llenos de símbolos culturales y de significaciones basadas en la vida cotidiana" (Barabas, 2010:48), así la comprensión del territorio, desde lo simbólico-cultural en la interacción humano/naturaleza asumida por las comunidades indígenas, está totalmente contrapuesta a la visión del capital o del Estado (Haesbaerth, 2013).

El territorio es un espacio geográfico culturalmente construido, receptor de elementos sociales de significación en el que se asientan usanzas, tradiciones, memorias, liturgias y formas diversas de organización, de manera que cada territorio se va conformando como propio de cada grupo específico. El espacio territorial refiere a la topografía, así como a las relaciones del tejido social en cuanto a su cultura, creencias y representaciones (Barabas, 2010). Bajo el manto de la legalidad, la reforma energética promueve y ampara la comercialización de los territorios de pueblos originarios y campesinos al mejor postor.

\section{Metodología}

La comunidad El Remolino fue elegida para esta investigación debido a la importancia de la producción de petróleo en su territorio. Cuenta con cuatrociencos pozos petroleros, de los 3220 que existen en el municipio de Papantla, algunos establecidos desde hace 50 años (SEGOB, 2010). Con el fin de analizar las implicaciones generales de la reforma energética sobre las condiciones territoriales, económicas y sociales en esta comunidad, se consultó información estadística del Registro Agrario Nacional, la Secretaría de Economía, la Secretaría de Desarrollo Social, la Secretaría de Energía y PEMEX. Debido a que la presente investigación es un estudio de caso, ya que se enfoca en conocer y analizar la realidad de una problemática particular, se consideró pertinente la utilización de fuentes primarias técnicas como la entrevista semiestructurada y la observación participante (Quinto, 2000; Rodríguez et al., 2017); se aplicaron cuestionarios a cuarenta ejidatarios (27.21\% del total) mediante una entrevista semiestructurada colectiva con la asistencia de catorce ejidatarios, y otra con diez integrantes del Grupo de Ecoturismo El Remolino S.C. de R.L. de C.V., lo que se completó 
con la observación directa durante octubre de 2015 a abril de 2016.

La observación participante (Quinto, 2000) se realizó en tres etapas: una fase exploratoria, que tuvo como objetivo detectar los elementos principales de la situación social estudiada, así como la distribución espacial mediante la observación y recorridos exploratorio; una segunda fase descriptiva que tuvo como objetivo conocer la actividad de PEMEX y su relación con los aspectos socioeconómicos y culturales de la población de estudio mediante la realización de entrevistas; y una tercera, que tuvo como objetivo analizar la configuración, transformación y complejidad de los procesos sociales que los sujetos efectúan a través del tiempo y el espacio, y se enfocó en establecer un proceso de retroalimentación constante encaminada a percibir cómo la población resiste, admite o asimila los trabajos de PEMEX en la comunidad.

Se consideró pertinente la aplicación de entrevistas a informantes clave a partir de un cuestionario base conformado por dieciséis preguntas, las cuales consideraban elementos como: nombre, edad, escolaridad, estado civil, ocupación, actividades desarrolladas, número de hijos, posesión de tierras, afectación de superficie por los trabajos de PEMEX y percepción sobre las distintas actividades de la paraestatal en su territorio. En un primer momento se priorizaron las visitas a las principales autoridades de la comunidad, de manera que se pudo ubicar a informantes clave, algunos de los cuales ocupaban cargos en la organización interna del pueblo.

También se consideraron testimonios de cuarenta pobladores que contaban con determinadas características como poseer tierras bajo su cargo y que estas tuvieran alguna afectación por los trabajos de PEMEX. La información que las personas entrevistadas proporcionaron fue complementada con los datos que se reunieron a partir de documentos escritos y material fotográfico. Se grabaron en audio las entrevistas semiestructuradas, donde la población narró sus percepciones y vivencias en relación con los trabajos de PEMEX en la comunidad, posteriormente se procedió a transcribirlas, y con esta base se realizó un trabajo principalmente descriptivo. Almeyra (2000) indicó que las entrevistas deben corroborarse a la luz de los documentos (confirmarlos y completarlos) y deben ser coherentes entre sí y ser interpretadas, lo que da gran valor a los significados implícitos y ocultos.

En cuanto a información documental, se revisaron diversos materiales hemerográficos, académicos y de investigación sobre la temática, además de información oficial proporcionada por distintas instituciones gubernamentales municipales, estatales y federales.

\section{Aspectos territoriales, sociales y económicos y sus implicaciones en la región de estudio}

Para entender y dimensionar la problemática de estudio es importante hacer referencia a una serie de temas importantes como la caracterización de la región de estudio en aspectos sociales y económicos, y particularidades vinculadas con la producción de hidrocarburos.

\section{Territorio en riesgo}

Elcapital ha dominadoal ser humanoy se ha aprovechado delos recursos naturales de formas diversas durantelargo tiempo; la nueva fase de acumulación por desposesión amenaza a millones de pobladores de muy diversos sectores (Harvey, 2005). Un claro ejemplo de ello son las reformas estructurales que han sido convenidas en gran parte del territorio latinoamericano. En México, la adecuación en los años 2013 y 2014 del marco jurídico que regula lo concerniente a la exploración, explotación y producción de hidrocarburos ha marcado una nueva etapa de profundas restructuraciones socioterritoriales.

El objetivo principal de las reformas y las adiciones decretadas en materia de energéticos (hidrocarburos, energía eléctrica y gas natural) se enfoca en la apertura del mercado energético a las grandes empresas transnacionales del sector, si bien es cierto que las adaptaciones jurídicas ratifican que la nación mexicana es la única titular del derecho de propiedad del petróleo y otros hidrocarburos, de manera que no es posible otorgar concesiones de ningún tipo a particulares para 
su aprovechamiento; sin embargo, sí faculta la firma de contratos de asignación entre el Estado y empresas privadas para llevar a cabo este tipo de actividades (Decreto por el que se reforman..., 2013).

Por su parte, la Ley de Hidrocarburos ordena un procedimiento especial, rápido y eficaz para los signatarios o contratistas que busquen acceder a tierras ejidales, comunales o privadas independientemente de la forma de tenencia de la tierra. Con estas disposiciones, se institucionalizó un procedimiento condensado de negociación entre grandes transnacionales y pueblos o individuos, muchas veces situados en condiciones de vulnerabilidad. La ley concede la opción de solicitar la asesoría y, en su caso, la representación de la Procuraduría Agraria en las negociaciones en las que estén involucrados núcleos y sujetos agrarios (Ley de Hidrocarburos, 2016).

La nueva etapa de "contrarreforma agraria" (Valdivia, 2011:38) al artículo 27 constitucional de 2013 crea un contexto totalmente diferente para los afectados por dicha servidumbre de hidrocarburos u ocupación temporal del suelo, ya que jurídicamente la acción de expropiación fue excluida de esta modificación debido a que la tierra es ocupada temporalmente mientras la actividad exploratoria y extractiva sea redituable para las empresas, las cuales tienen un carácter evidentemente migratorio ya que cuando los yacimientos se agotan dirigen su actividad a tierras más prosperas con nuevos yacimientos, dejando atrás las tierras improductivas explotadas (Núñez, 2017).

Estos cambios legislativos modificaron la estructura agraria del país vulnerando los derechos de los campesinos y de la población rural en general, toda vez que importantes extensiones de tierra dejaron de estar en posesión de ejidos y comunidades para ser ocupadas por la industria energética, tanto en el área de hidrocarburos (exploración y extracción) como en la de energía eléctrica (eólica e hidroeléctrica), al ser consideradas actividades de carácter estratégico y "de interés público, por lo que tendrán preferencia sobre cualquier otra que implique el aprovechamiento de la superficie y del subsuelo de los terrenos afectos a aquéllas" (Decreto por el que se reforman..., 2013). En particular, en el estado de Veracruz se implementaron gran número de megaproyectos de producción de petróleo contemplados en el plan de la reforma energética (Secretaría de Energía, 2018a).

Históricamente, Veracruz ha sido uno de los principales estados productores de petróleo, gas natural y derivados al concentrar gran parte de la petroquímica nacional (Ibarra, 2003). Sin embargo, tras los megaproyectos impulsados con la reforma energética de 2013 y la Ley de Hidrocarburos de 2014, y considerando las proyecciones de la Secretaría de Energía, PEMEX y la Comisión Nacional de Hidrocarburos, todo indica que la actividad extractiva podría aumentar hasta el doble o triple de lo que actualmente se registra (Secretaría de Energía, 2018a y 2018b). Además de las rondas 0 y 1 se tienen planeadas para la exploración o extracción de hidrocarburos las rondas 2, 3 y 4 (ver Mapa 1).

El ejido El Remolino se ubica en la región sureste del municipio de Papantla de Olarte a 26 kilómetros de la cabecera municipal, en las márgenes del río Tecolutla. Fue constituido por la acción de dotación publicada el 25 de enero de 1924 que benefició a 70 ejidatarios. Se llevaron a cabo dos acciones de ampliación: la primera, el 22 de abril de 1948, que favoreció a 39 personas y; la segunda, el 26 de marzo de 1987, que benefició a 37 personas. En 2018, El Remolino estaba constituido por 147 ejidatarios, 58 avecindados y 109 posesionarios con una superficie de 1377.09 hectáreas (RAN, 2018). En cuanto a organización interna, la estructura comunitaria está conformada por el agente municipal, el comisariado ejidal, el Comité de Padres de Familia y el Comité de Ecoturismo El Remolino.

\section{Aspectos sociales}

En 2010, El Remolino contaba con una población de 1225 personas, 613 mujeres y 612 hombres, de las cuales el 69\% eran indígenas totonacas hablantes de totonaco y de español. El 30.49\% del total de la población de 15 años o más no tenía primaria completa y el 9.21\% era analfabeta. El 14.2\% de la población no disponía de acceso a servicios médicos debido a que no se habían 
registrado en la unidad médica de la comunidad. De las 293 viviendas, el 3.41\% no contaba con servicio de sanitario, el 6.14\% no tenía energía eléctrica, el 49.83\% carecía de drenaje y el $\mathbf{9 8 . 9 8 \%}$ de servicio de agua entubada. La comunidad presentaba un alto grado de marginación (SEDESOL, 2013).

Con relación al agua, las personas entrevistadas manifestaron que la población utilizaba el agua de manantiales y de seis pozos públicos para el consumo cotidiano (consumo humano, bañarse, lavar la ropa y trastes, cocinar alimentos, consumo animal y regar cultivos). Para el consumo humano y para cocinar traían el agua del "chorrito" por medio de una tubería que se conectaba con un manantial, actividad realizada por mujeres y niños: "La mayor parte del rancho tomamos agua de manantiales, tenemos muchos manantiales, la mayoría de la gente consume esa agua para guisar, para todo..." (testimonio de Isidora Hernández).

El Remolino tenía una unidad médica rural del Instituto Mexicano del Seguro Social que sufría de saturación de personas en espera de ser atendidas, en su mayoría mujeres y niños. Se percibían deficiencias en las instalaciones y en el servicio. Contaba con una ambulancia donada por PEMEX para servicios de traslado de enfermos. En la comunidad había un rezandero que utilizaba las plantas medicinales para tratar algunos problemas de salud como dolor de estómago, empacho, gastritis, espanto, fiebre, dolor de muelas y huesos. El conocimiento y uso de las hierbas medicinales es parte del legado ancestral de las culturas originarias y continúan siendo usadas por muchas personas para aliviar sus dolencias.

En materia de educación, la comunidad disponía de dos escuelas de educación preescolar que impartían la instrucción en español y totonaco. Diversas obras de rehabilitación en estas escuelas fueron patrocinadas por PEMEX. Además, contaba con la escuela primaria federal Benito Juárez que tenía un comedor gratuito para el estudiantado del plantel.

Las obras de rehabilitación efectuadas se anunciaban en las placas conmemorativas colocadas en la entrada de cada plantel. Así lo corroboró el presidente del Comisariado Ejidal, quien aseguró que estas obras eran algunos de los pocos beneficios que PEMEX había otorgado a la población. La comunidad contaba también con una telesecundaria y un telebachillerato, ambos centros con poca infraestructura, algunos estudiantes se veían en la necesidad de trabajar los fines de semana en el restaurante Min-chik, ubicado dentro del proyecto de ecoturismo El Remolino, para mantener sus estudios.

\section{Actividades económicas}

En El Remolino, el 25\% de los ejidatarios tiene menos de cuatro hectáreas y solo el 10\% tiene más de 20; estos últimos compran tierras a otros ejidatarios, lo que indica que existe un mercado interno de tierras ejidales. La principal actividad económica del ejido es el cultivo de naranja, a la que se dedica el 98\% de los ejidatarios de la comunidad. Además, cultivan entre los naranjales, en sistema de policultivo, maíz, tomate, chile piquín, frijol y pipían para el consumo familiar. La comunidad cuenta con suficiente agua para riego, incluso varias de las parcelas poseen manantiales, ojos de agua o pequeños arroyos que, sin embargo, presentan problemas de contaminación. Las familias cuentan con animales de traspatio como gallinas, patos, guajolotes y puercos.

El 20\% de los ejidatarios realiza actividades complementarias a la agricultura con el fin de completar el gasto familiar; el 10\% de ellos tiene pequeños molinos de nixtamal, con los que generan ingresos extras por la venta de masa. El 45\% de las familias de ejidatarios tiene, en promedio, un integrante en Estados Unidos (esposo o hijo), reclutados de forma legal en los programas de jornaleros agrícolas promovidos en la región. A este respecto, autoridades municipales comentaron que los jóvenes emigraban por falta de empleos en la comunidad.

\section{De la vainilla al pozo petrolero}

La vainilla, cultivo prehispánico en la zona totonaca del norte de Veracruz y Puebla, ha ocupado un lugar especial ya que en torno a ella giran una serie de tradiciones religiosas, representa para los totonacas lo que el maíz para los aztecas. En la cosmovisión del pueblo totonaca se interpreta la vinculación ser 
humano-naturaleza como una convivencia, por ello, antes de la cosecha de la vainilla realizaban una serie de reverencias en agradecimiento por el producto obtenido. En las culturas maya y azteca, la vainilla se agregaba a una bebida elaborada con cacao que consumían los nobles y los guerreros, los pueblos conquistados la ofrecían como tributo a los aztecas. En el cultivo tradicional de la vainilla, las flores deben ser polinizadas una vez al año de manera manual con la ayuda de una espina de naranjo o de una madera en forma de punta. Una vez cosechadas manualmente las vainas, son calentadas para interrumpir el proceso de maduración del fruto y después se ponen al sol durante 150 días para su secado. Actualmente, nueve de las quince especies de vainilla mesoamericana que existen se cultivan en México (SAGARPA, 2017; Soto, 2006).

Cabe señalar que la Secretaría de Economía otorgó a la vainilla de Papantla la denominación de origen. La declaratoria de protección fue publicada en el Diario Oficial de la Federación el 24 de febrero de 2009. Esta denominación de origen ampara a la orquídea planifolia Andrews, así como las variedades conocidas como vainilla Fina o Mansa, con diversos subtipos como Cazones, Zozocolco, Tarro o Acamaya, Oreja de Burro y Rayada. La vainilla se produce en una superficie de 7751 kilómetros cuadrados en 39 municipios de los estados de Veracruz y Puebla (Secretaría de Economía, 2016).

En 1987, El Remolino era considerado como región productora de vainilla (Secretaría de Economía, 2016). Los representantes ejidales mencionaron que, antes de la presencia de PEMEX en la comunidad, todas las familias tenían plantíos de vainilla, pero que actualmente ya no se produce para fines de mercado. Además, los trabajos de PEMEX habían ocasionado que los campesinos dejaran de producir por la afectación ambiental del suelo y del agua: "Cuando no estaba PEMEX había animales y se tenían buenas cosechas, pero cuando entró la maquinaria se fueron y ahora los campesinos ya no cultivan sus tierras" (testimonio de Santos Hernández de Luna).

La comercialización de la vainilla en la comunidad ha desaparecido casi por completo; no obstante, algunos campesinos aún conservan orquídeas de vainilla en sus parcelas, pero sin el propósito de comercializarlas, lo hacen por el gusto de cosechar el fruto y transmitir el conocimiento del proceso productivo de la vainilla a sus hijos: "Sembraba la vainilla con mi abuelo, es algo que me llamaba la atención, mucha gente está perdiendo esa costumbre, alguna que otra todavía lo conserva, yo incluso tengo unas matas entre los naranjos para no perder la costumbre de cultivarlas" (testimonio de Margarito Pérez Pérez).

Los campesinos de la comunidad relacionan la erosión de la tierra y la disminución de la producción de la vainilla y el maíz, así como el descenso de la fauna local con el aumento de los trabajos de PEMEX. Manifestaron que los constantes derrames de químicos, así como las emisiones de humo, han dañado severamente el medioambiente en la comunidad. De acuerdo con Boege (2008), el daño ambiental no solo afecta la biodiversidad sino que acelera los procesos de desertificación y contaminación del agua y el suelo.

Los trabajos de PEMEX en El Remolino: daños y beneficios

Desde 1982, PEMEX realizó diversas actividades en la comunidad de El Remolino, como la construcción de caminos para el tránsito de camiones, maquinaria y transporte de empleados, de líneas de conducción de hidrocarburos, de pozos de chapopote y de plataformas de extracción, así como la fabricación de depósitos de crudo; ello junto con la implementación de procedimientos para la exploración de hidrocarburos (PEMEX, 2012).

Autoridades municipales, ejidales y representantes del Grupo de Ecoturismo El Remolino, basándose en documentos y mapas de la comunidad, afirmaron que para 2016 existían cuatrocientos pozos petroleros en el ejido. Se ubicaban alrededor del pueblo y dentro de las parcelas, en los denominados "cuadros", que constituyen el espacio ocupado por la plataforma y los aditamentos necesarios para su funcionamiento. El tamaño de cada ocupación depende del tipo de plataforma u obra que se ejecute, la extensión de cada plataforma oscila entre 1.5 y dos hectáreas. Se observó 
que dentro del área de asentamiento humano había tres plataformas, una de las cuales se terminó de construir a finales de 2015 ocupando una superficie de 1.5 hectáreas.

El 90\% de los ejidatarios tiene afectaciones dentro de sus parcelas. Con los trabajos de exploración realizados en 2014 y 2015, según versiones de las autoridades ejidales, se dinamitaron algunas tierras ejidales en busca de indicios de nuevos yacimientos de hidrocarburos.

Las indemnizaciones que PEMEX ha otorgado en la comunidad cubren un monto por cada árbol que derriba, cuyo valor aproximado, de acuerdo con los afectados, oscila entre 300 y 800 pesos dependiendo de la edad del árbol. Al respecto, el comisario ejidal señaló que PEMEX en ocasiones no quería reconocer los daños, de tal forma que algunas personas se veían obligadas a hacer gestiones administrativas tediosas para que les pagaran: "PEMEX a veces no quiere reconocer los daños, hay compañeros que tienen afectaciones y batallan para que les paguen, andan detrás de ellos para que les paguen" (testimonio del comisario ejidal Margarito Pérez Pérez); "Trabajadores de PEMEX entraron varias veces a los terrenos de un tío y él pedía que le pagaran los daños, a lo cual siempre se negaban; un día intentaron entrar a su terreno pero él no se los permitió" (testimonio de Mariana Valencia Pérez).

Respecto a los derrames y la contaminación, los entrevistados manifestaron que han sido varios los percances que se han presentado. Uno de los más graves se produjo en 2010, cuando ocurrió un derrame de crudo en las aguas del río Tecolutla debido a la ruptura de una línea con hidrocarburo. PEMEX realizó trabajos de limpieza durante un mes en el área afectada; sin embargo, la población no recibió ningún tipo de indemnización o apoyo por la contingencia y, lo más grave, se registró una disminución de especies acuáticas. Ese suceso era muy bien recordado por los pobladores: "El derrame que hubo en el río estuvo bien feo, contaminó todo, mató a todos los animales que había; llegaron los de PEMEX y empezaron a limpiar el río, nos dijeron que se reventó un tubo pero no dieron ninguna indemnización" (testimonio de Susana Santiago García).
En 2015 se suscitó otro accidente debido a la ruptura de una de las tuberías que transportaba el crudo, ocasionó la contaminación del arroyo, manantiales cercanos y de los seis pozos públicos que abastecían de agua para el consumo a la comunidad. Representantes ejidales manifestaron que existían tuberías rotas sin mantenimiento, lo que ocasionaba contaminación del suelo, el agua, la flora y la fauna. Expusieron que tanto PEMEX como las empresas contratistas que colaboraban con la paraestatal no habían pagado por los daños ocasionados en los incidentes: "PEMEX contaminó el agua pero no lo quiso reconocer ni indemnizar; la contaminación llegó hasta donde tenemos el cárcamo, el agua, y los terrenos de cultivo se contaminaron, solo recomendaron que no utilizáramos esa agua porque estaba contaminada" (testimonio del comisariado ejidal Margarito Pérez Pérez).

Las afectaciones al ecosistema han repercutido en la salud de las personas que viven en la comunidad, siendo los niños los más afectados ya que constantemente presentan cuadros infecciosos de distintos tipos: "Nosotros ya no tomamos agua del manantial porque mi hermanito se la pasaba enfermo y a mí también me hacía daño; entonces, ya utilizamos el agua de garrafón para beber (testimonio de Mariana Valencia Pérez).

A pesar de los graves problemas de contaminación presentados, solo el 10\% de la población optaba por no consumir agua del manantial y recurría a la compra de agua embotellada para consumo humano. Aunque no se habían efectuado pruebas de laboratorio que demostraran que estos problemas de salud tuvieran como causa el consumo de agua contaminada con residuos tóxicos, la lógica llevaba a concluir tal supuesto por lo observado y los testimonios obtenidos.

Además de la contaminación del agua, el suelo sufría daños debido al derrame de hidrocarburos, lo que ocasionaba el deterioro de las tierras de cultivo. El área cercana a los pozos o plataformas se tornó ruinosa y con fétido aroma que desprendían los pozos de petróleo y de alquitrán.

Con base en lo observado y en los testimonios de los entrevistados, la presencia de PEMEX generó algunos beneficios como la rehabilitación de las dos escuelas 
de educación preescolar, la construcción del comedor de la escuela primaria y del auditorio de la comunidad, y la apertura y pavimentación de carreteras y caminos que conectaban sus múltiples plataformas. Las veredas fueron sustituidas por carreteras que permitían también un acceso fácil y rápido a las parcelas, lo que beneficiaba a los productores para la comercialización de sus cosechas. Sin embargo, los habitantes de la comunidad están conscientes de la gravedad de los problemas que enfrentaban y consideraban que la ayuda otorgada por PEMEX había sido poca en comparación con los daños provocados. Afirmaron que, a partir de la reforma energética de 2013, se incrementaron los costos de la energía eléctrica, a la vez que aumentaron las actividades exploratorias y el deterioro ambiental.

Sobre los nuevos trabajos de exploración y explotación planificados por PEMEX en la comunidad, las autoridades ejidales y municipales refirieron que, según mapas que les habían proporcionado, se preveía la apertura de nuevos pozos y plataformas: "Me dieron una lista de los pozos que iban a funcionar, los que se van a reactivar y otros trescientos que iniciarán sus actividades, marcados con números rojos y nombre de los dueños que serán afectados" (testimonio de Pedro Pérez Ticante).

En síntesis, se puede señalar que la entrada de capital, vía proyectos de PEMEX, al ejido El Remolino, no ha generado desarrollo local endógeno debido a la carencia de políticas públicas de inclusión y de organización de la población, elementos necesarios para el desarrollo regional también considerados por Boisier (2005), Rodríguez et al. (2017), Rojas, Cardona y Gallego (2017) y Vázquez-Barquero (2000).

\section{Territorio comunitario}

La Comisión Nacional para el Desarrollo de los Pueblos Indígenas (CDI, 2012) promueve los servicios del centro ecoturístico denominado Grupo de Ecoturismo El Remolino S.C. de R.L. de C.V. como parte de sus programas de turismo alternativo para zonas indígenas. El grupo ha trabajado desde 2013 y está conformado por 30 integrantes originarios de la comunidad, cada uno de los cuales realiza distintas tareas como las siguientes: cocinar, hacer el aseo general, brindar atención a clientes, hacer el rol de velador, vender artesanías, guiar al turismo y servir en el restaurante, así como cubrir las funciones de gestión, de tesorería o de dirección de la organización. Los integrantes del grupo comentaron que había un puesto de trabajo destinado para los hijos de cada persona asociada. Además, con el grupo colaboraban también algunos jóvenes del pueblo que apoyaban en las labores de la cocina únicamente los sábados y los domingos ya que entre semana asistían a la escuela telesecundaria de la comunidad.

El grupo cuenta con cabañas para el servicio de hospedaje y con una tienda de artesanías donde se ofrecen a los visitantes prendas de vestir y bolsas bordadas a mano, así como diversos objetos de cerámica, barro y madera. Algunas de estas artesanías son elaboradas por personas de pueblos vecinos que traen sus productos para su venta en el lugar.

Respecto a la gastronomía, en el centro se encuentra el restaurante Min-chik (mi casa) se sirven platillos típicos de la cultura totonaca (CDI, 2012). Las "mayoras", cuyas recetas se han transmitido de generación en generación, son las encargadas de elaborar los alimentos. Los ingredientes que utilizan proceden casi en su totalidad de sus propias cosechas. Las variedades de pescado servidas en el restaurante se obtienen del río Tecolutla o del criadero de peces colindante que está a cargo de otro colectivo integrado también por pobladores de El Remolino. Este proyecto productivo recibió apoyo de PEMEX para la construcción de los estanques, según consta en las placas colocadas en la entrada de cada construcción.

El Grupo El Remolino tiene a su cargo la reserva ecológica de Talhpan, tiene una superficie de 24 hectáreas. Ofrece actividades de senderismo, paseos en pangas (lanchas) a lo largo del río Tecolutla, pesca y rapel. A lo largo de la reserva transcurre un arroyito que forma pequeños estanques de agua. Los integrantes del grupo manifestaron que PEMEX se comprometió a modernizar la infraestructura del parque ecológico con la construcción de una tirolesa, varios puentes colgantes y un embarcadero, cuyos trabajos se venían realizando desde 2015 según se pudo constatar en 
uno de los recorridos. La participación del Comité de Ecoturismo en la organización interna de la comunidad es muy importante ya que constituye un referente en la toma de decisiones colectivas.

El encuentro del capital con la población rural en un mismo espacio ha generado una restructuración del territorio que ha traído consigo un cambio en las relaciones sociales y económicas de la comunidad. Este choque de dos procesos, con determinaciones socioeconómicas desiguales, ha generado distintas trasformaciones y diversificación en el patrón de actividades de los campesinos y sus familias, con tareas ajenas a la agricultura como ocurrió en el caso de El Remolino.

Los fundadores del grupo mencionaron que la reserva ecológica cuenta con árboles antiguos de variedades como jonote, laurel, cedro (que los pobladores utilizan para hacer rituales de limpias) y ceiba, además de papaya y una gran variedad de plantas medicinales y de frutales. Entre las plantas medicinales destaca la chaca o palo mulato que se utiliza para el alivio de la fiebre, la albahaca que se usa para curar el espanto y para desparasitar, y otras como la pata de rana, la cola de caballo y la barquilla que se usa para lavar heridas. El empleo de las plantas medicinales en El Remolino es un legado ancestral, es un saber que ha sido transmitido de manera milenaria y que aún permanece en nuestros días.

Dentro de la Reserva Ecológica de Talhpan existe un espacio llamado la Cueva de los Murciélagos. Es un lugar cargado de símbolos y significaciones culturales, religiosas y espirituales; el curandero del pueblo desarrolla rituales de sanación a los que asisten personas de la comunidad y de otros pueblos para pedir por la salud o el trabajo. En el lugar se encuentran veladoras, bebidas, inciensos, flores e imágenes religiosas, símbolos y significaciones culturales que forman parte de su identidad cultural. Los rituales y ceremonias que se realizan revelan la conexión intrínseca que los pueblos y comunidades indígenas y campesinos mantienen con su territorio, así como los procesos de construcción y apropiación de territorios desde la esfera cultural (Haesbaerth, 2013).
Durante el trabajo de campo se realizó una entrevista colectiva con catorce ejidatarios mientras elaboraban "estrellas", una figura bidimensional tejida en forma de estrella elaborada con hoja de palma de coyol, que es una especie propia de la región. Mientras se realizaba la entrevista, además de sus testimonios sobre la actividad de PEMEX en el ejido, los tejedores manifestaron lo importante que son las "estrellas" para su cultura ya que con ellas se adorna una estructura en forma de arco que simula la puerta por donde cruza el alma de los muertos hacia el otro mundo. Este arco se coloca tanto al interior de la casa de la persona fallecida, a manera de ofrenda, como en su sepultura.

Los entrevistados manifestaron que no les gustaría ver afectadas nuevamente sus parcelas con los proyectos que impulsa la reforma energética ya que consideran que los daños superan en mucho a los pocos beneficios que se obtienen como indemnizaciones personales o algunas obras materiales para la comunidad. Afirmaron que incluso la elaboración de estrellas se afectaría porque hasta las palmas de coyol serían derribadas para abrir paso a las plataformas petroleras.

\section{Conclusiones}

Las actividades de PEMEX en la región de estudio han ocasionado erosión del suelo, contaminación del suelo y del agua, descenso de la fauna local endémica y deterioro del cultivo de la vainilla y del maíz, lo que incide negativamente en las condiciones de vida de los pobladores.

En El Remolino, debido a los derrames de hidrocarburos se han visto dañadas las fuentes naturales de agua que abastecen a la comunidad, lo que ha repercutido negativamente en la producción agrícola, en el abasto de agua para el consumo humano y en la salud de los pobladores. Los planteamientos relacionados con la afectación sobre la producción agrícola, sobre el agua y sobre la salud humana como consecuencia de la contaminación ocasionada por PEMEX en el territorio de la comunidad dan pie a diversos temas para nuevas investigaciones ya sea desde el enfoque ambiental e hídrico o desde el enfoque de la salud humana. 
Existe desatención por parte de los gestores de PEMEX y de las compañías contratistas que trabajan con la paraestatal ya que los ejidatarios que tienen tierras afectadas por los proyectos de la empresa pasan dificultades para recibir las indemnizaciones en los casos en los que se suscitan problemas.

La actividad agrícola en El Remolino se enfrenta a una crisis debido a la falta de recursos de los productores, por lo que la diversificación ocupacional a través de actividades ajenas a la agricultura ha sido fundamental para la subsistencia de los pobladores y la permanencia de las parcelas familiares. Los proyectos productivos que se llevan a cabo en El Remolino condensan estas estrategias de sobrevivencia, de adaptación y de resistencia de los pobladores a dejar su tierra, sus modos de vida y su comunidad. Estos proyectos constituyen un referente importante de autogestión alternativa, auténticamente creado y desarrollado por pobladores de la comunidad, lo que permite a la población obtener ingresos extras sin perder el vínculo con la tierra y, sobre todo, sin abandonar la comunidad, a la vez que fortalece y fomenta lazos de solidaridad y de cohesión social.

El Grupo de Ecoturismo El Remolino actúa como hilo conductor entre los procesos de supervivencia material y la defensa de las especificidades históricosociales y geográficas de sus integrantes ya que permite avivar y proyectar la identidad cultural de sus miembros, lo que a su vez constituye la base primordial de la conformación y desarrollo del propio proyecto.

A pesar de que PEMEX lleva más de cuarenta años trabajando en la comunidad no ha implicado ninguna mejoría en el nivel de ingresos y de servicios básicos de la población sobre todo en las áreas de educación $y$ de salud. Aunque existe un desconocimiento de los pobladores de El Remolino sobre las implicaciones de la reforma de 2013 en materia de energéticos en sus territorios, principalmente en la ejecución de los trabajos de exploración y extracción de hidrocarburos, no se presentan acciones concretas de oposición a la ejecución de los proyectos de este tipo en la comunidad. Asimismo, se puede percibir un descontento en los pobladores del ejido que se muestran reacios a aceptar nuevos proyectos para la extracción de hidrocarburos en su territorio, a la vez que está latente la preocupación por la ejecución de fracking, lo cual indica que podría generarse un frente de resistencia social a los nuevos proyectos extractivos en la zona.

En El Remolino la identidad cultural de los pobladores está íntimamente relacionada con la naturaleza, lo cual enfatiza el importante vínculo que existe entre su territorio, su cosmovisión y sus modos de vida, a la vez que indica que los deterioros materiales que se generen en su territorio con el aumento de la actividad extractiva influirán también sobre su tejido sociocultural.

Finamente, el incremento de la actividad petrolera que se tiene previsto así como el uso de técnicas invasivas como el fracking, provocará una mayor ruptura territorial y deterioro en la dinámica social, cultural y política de quienes habiten los territorios invadidos. Con la entrega de los territorios a empresas transnacionales para su explotación, a través de la reforma energética de 2013, los pueblos originarios y sus tradiciones tienden a desaparecer, a la vez que se mercantilizan las relaciones sociales, culturales y espirituales de pueblos, etnias y de personas integrantes de cada comunidad arraigados en esos territorios.

\section{Referencias}

Alburquerque, Francisco (2004). El enfoque del desarrollo económico local. Buenos Aires: Organización Internacional del Trabajo.

Almeyra, Guillermo (2000). "Estudio histórico social: cómo interrogar”. En R. Quintana (coord.), Investigación social rural buscando huellas en la arena. México: Plaza y Valdez, pp. 35-41.

Barabas, Alicia (2010). "El pensamiento sobre el territorio en las culturas indígenas de México". En Avá. Revista de Antropología, 17, julio-diciembre, 1-15.

Boege, Eckart (2008). El patrimonio biocultural de los pueblos indígenas de México. México: Instituto Nacional de Antropología e Historia/Comisión Nacional para el Desarrollo de los Pueblos Indígenas. 
Boisier, Sergio (2005). "iHay espacio para el desarrollo local en la globalización?”. En Revista de la Cepal, 86, agosto, 47-62.

Cartocrítica (2014). Hidrocarburos: Ronda Cero y Ronda Uno. México: Cartocrítica, 2 de octubre. Disponible en: http://www.cartocritica.org.mx/2014/hidrocarburosronda-cero-y-ronda-uno/ (consultado el 20 de junio de 2018).

CDI (Comisión Nacional para el Desarrollo de los Pueblos Indígenas) (2012). Unidadecoturísticael Remolino. México: CDI. Disponible en: http:/www.cdi.gob.mx/turismo/ index.php?option=com_content\&eview=article\& $\&$ id=130 :unidad-ecoturistica-el-remolino\&ecatid=49:veracruz\&EItemid=54 (consultado el 20 de junio de 2018).

Constitución Política de los Estados Unidos Mexicanos (2018). México: Cámara de Diputados. Disponible en: http://www.diputados.gob.mx/LeyesBiblio/ref/ cpeum.htm (consultado el 21 de junio de 2018).

Decreto por el que se reforman y adicionan diversas disposiciones de la Constitución Política de los Estados Unidos Mexicanos, en Materia de Energía (2013). EnDiarioOficialdela Federación, 20 de diciembre. Disponible en: http://dof.gob.mx/nota_detalle.php?c odigo $=5327463 \&$ efecha=20/12/2013 (consultado el 19 de junio de 2018).

Giménez, Gilberto (1999). "Territorio, cultura e identidades. La región socio-cultural”. En Estudios sobre las Culturas Contemporáneas. Revista de Investigación y Análisis, 9, junio, 25-57.

Haesbaert, Rogério (2013). "Del mito de la desterritorialización a la multiterritorialidad". En Cultura y Representaciones Sociales, 8(15), 9-42.

Harvey, David (2005). El "nuevo" imperialismo: acumulación por desposesión. Buenos Aires: CLACSO

Harvey, David (2007). Breve historia del Neoliberalismo. Madrid: Akal.

Ibarra, Rosalía (2003). Laexplotaciónpetroleramexicana frente a la conservación de la biodiversidad en el régimen jurídico internacional. México: Instituto de Investigaciones Jurídicas-UNAM.

Lawson, Clive (2013). "Hacia una teoría de competencia regional". En Marcos Valdivia y Javier Delgadillo (coords.), Lageografíay la economía en sus vínculos actuales.
Una antología del debate contemporáneo. México: Centro de Investigaciones Económicas-UNAM, Centro Regional de Investigaciones MultidisciplinariasUNAM, pp. 477-494.

Ley de Hidrocarburos (2016). México: Cámara de Diputados del Honorable Congreso de la Unión. Disponible en: http:/www.diputados.gob.mx/ LeyesBiblio/pdf/LHidro_151116.pdf (consultado el 19 de junio de 2018).

Luxemburgo, Rosa (1967). La acumulación del capital. México: Grijalbo.

Nuñez, Elvira (2017). “(Contra) reforma agraria y megaproyectos de hidrocarburos: implicaciones jurídicas y socioterritoriales de la reforma energética de 2013". En Ensayos y Artículos de Sociología Rural, 12(23), enero-junio, 117-133.

PEMEX (Petróleos Mexicanos) (2012). Contratos integrales exploración y producción. México: PEMEX. Disponible en: http://contratos.pemex.com/chicontepec/Paginas/ default.aspx (consultado el 20 de junio de 2018).

Quinto, María (2000). "Historia oral e historias de vida en el campo". En Estudios sobre las Culturas Contemporáneas. Revista de Investigación y Análisis, 6(11), junio, 135-142.

RAN (Registro Agrario Nacional) (2018). Padrón e historial de núcleos agrarios. México: RAN. Disponible en: http://phina.ran.gob.mx/phina2/ (consultado el 20 de junio de 2018).

Rodríguez, Adrián, Pablo Galoso, Sebastián Goinheix y Camilo Martínez (2017). Especializaciones productivas y desarrollo económico regional en Uruguay. Montevideo: Instituto de Economía, Facultad de Ciencias Económicas y Administración, Universidad de la República. Serie Documentos de Trabajo, DT 07/2017.

Rodríguez, Emilio (2014). "A la Vera de la resistencia socioambiental". En La jornada del campo, 86, 15 de noviembre. Disponible en: http://www.jornada. unam.mx/2014/11/15/cam-empresas.html (consultado el 20 de junio de 2018).

Rojas, Iván, John Cardona y José Gallego (2017). "Estrategias de desarrollo económico local para el municipio de Girardota”. En Revista CEA, 3(6), 2945. DOI: https://doi.org/10.22430/24223182.770 (consultado el 21 de junio de 2018). 
SAGARPA (Secretaría de Agricultura, Ganadería, Desarrollo Rural, Pesca y Alimentación) (2017). Planeación agrícola nacional 2017-2030. México: SAGARPA. Disponible en: https://www.gob.mx/ cms/uploads/attachment/file/257086/PotencialVainilla.pdf (consultado el 26 de agosto de 2018).

Secretaría de Economía (2016). ¿Sabías que la vainilla de Papantla tiene denominación de origen? México: Secretaría de Economía. Disponible en: https://www.gob.mx/ se/articulos/sabias-que-la-vainilla-de-papantla-tienedenominacion-de-origen (consultado el 19 de junio de 2018).

Secretaría de Energía (2018a). Programa quinquenal de licitaciones para la exploración y extracción de hidrocarburos 2015-2019. México: la Secretaría. Disponible en: http:// www.gob.mx/sener/acciones-y-programas/programaquinquenal-de-licitaciones-para-la-exploracion- $y$ extraccion-de-hidrocarburos-2015-2019 (consultado el 19 de junio de 2018).

Secretaría de Energía (2018b). Ronda cero. México: la Secretaría. Disponible en: http://base.energia. gob.mx/dgaic/DA/P/SubsecretariaHidrocarburos/
RondaCeroMapas AreasOtorgadasPemex/ SENER_02_MapasRondaCero.pdf (consultado el 19 de junio de 2018).

SEDESOL (Secretaría de Desarrollo Social) (2013). Catálogo de localidades, sistema de apoyo para la planeación del PDZP. México: SEDESOL. Disponible en: http:// www.microrregiones.gob.mx/catloc/contenido. aspx?refnac=301240093 (consultado el 19 de junio de 2018).

SEGOB (Secretaría de Gobernación) (2010). Enciclopedia de los municipios y delegaciones de México. México: SEGOB. Disponible en: http://www.inafed.gob.mx/ work/enciclopedia/EMM30veracruz/index.html (consultado el 20 de junio de 2018).

Soto, Miguel (2006). "La vainilla, retos y perspectivas de su cultivo". En Biodiversitas, 66, 1-9.

Valdivia, Eloísa (2011). "Modelos de reforma agraria en América Latina”. En Libro 1: La problemática agraria. Quito: Consorcio Camaren, p. 38.

Vázquez-Barquero, Antonio (2000). Desarrollo económico local y descentralización: aproximación a un marco conceptual. Santiago: CEPAL. 
Mapa 1. Programa quinquenal de licitaciones para la exploración y extracción de hidrocarburos, 2015-2019

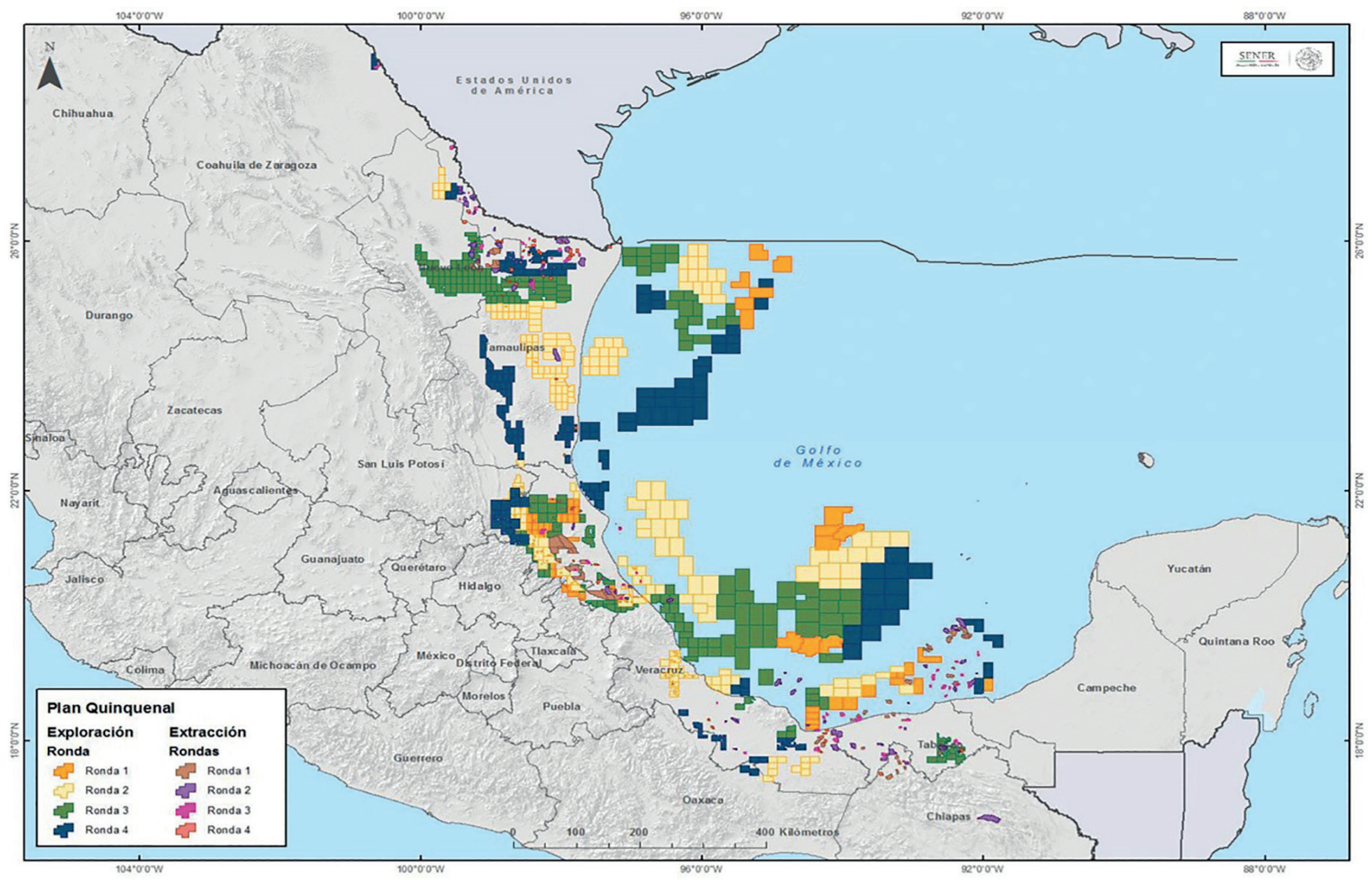

Fuente: Secretaría de Energía (2018b). 